\title{
Spotlight on glycopyrronium/formoterol fumarate inhalation aerosol in the management of COPD: design, development, and place in therapy
}

This article was published in the following Dove Press journal:

International Journal of COPD

3 August 2017

Number of times this article has been viewed

\section{Santosh Dhungana \\ Gerard J Criner}

Department of Thoracic Medicine and Surgery, Temple Lung Center, Lewis Katz School of Medicine at Temple University, Philadelphia, PA, USA
Correspondence: Santosh Dhungana Department of Thoracic Medicine and Surgery and Temple Lung Center, Lewis Katz School of Medicine at Temple University, 340I North Broad Street, Parkinson Pavilion suite 745, Philadelphia, PA 19|40, USA

Email santosh.iom@gmail.com
Abstract: Long-acting bronchodilators are the mainstay of the treatment of COPD. With the advent of several combination inhalers with long-acting antimuscarinic agents (LAMAs) and long-acting beta agonists (LABAs), the choice of therapy in the treatment of COPD has been ever expanding. With the focus of COPD management shifting from $\mathrm{FEV}_{1}$-based treatment escalation to symptoms and risk-based treatment, we are seeing a paradigm shift in COPD treatment with early introduction of LAMA-LABA combination as a single inhaler. Glycopyrronium/formoterol fumarate fixed-dose combination formulated in a familiar metered-dose inhaler format using proprietary co-suspension technology is a new option on the market. We purport to discuss the evidence behind the approval of the drug combination and its place in therapy.

Keywords: exacerbations, long-acting antimuscarinic agent, long-acting beta agonist, inhaled corticosteroids, formoterol fumarate, glycopyrronium, adverse events, metereddose inhaler

\section{Introduction}

COPD is a common cause of morbidity and mortality in both developing and developed countries. It is the fourth leading cause of death in the world according to WHO statistics ${ }^{1}$ and is predicted to be the third leading cause of death in the world by $2020 .^{2}$ It presents a significant economic burden to the society. The mainstay of COPD management has been long-acting bronchodilators including long-acting antimuscarinic agents (LAMAs) and long-acting beta agonists (LABAs), the latter frequently combined with inhaled corticosteroid (ICS). The initial 2001 Global initiative in Obstructive Lung Diseases (GOLD) guidelines recommended short-acting bronchodilators in patients with mild obstruction, long-acting bronchodilators (LAMA) in patients with moderate obstruction, and a combination of long-acting bronchodilators and ICS in those with severe obstruction and a history of frequent or severe exacerbations. However, physicians have increasingly realized that grading COPD severity and determining treatment based on spirometric values are simplistic, as there are patients across the spectrum of spirometric values who are very symptomatic and at high risk of frequent exacerbations. The most recent GOLD Report acknowledges this by categorizing COPD into different risk groups (A-D), and now recommends tailoring therapy to the patient's overall symptom burden and risk of adverse outcomes. ${ }^{3}$ Evidence suggests that ICS is beneficial in reducing frequent exacerbations but can probably be safely withdrawn in patients who are not at high risk of exacerbations. ${ }^{4}$ It is in this context that LAMA-LABA combinations are emerging, and a few studies 
have shown superiority of this combination to LABA-ICS combination in symptom control. There are five fixed-dose LAMA-LABA combination currently available, including formoterol/aclidinium, indacaterol/glycopyrronium, olodaterol/tiotropium, umeclidium/vilanterol, and formoterol/ glycopyrronium. Formoterol/glycopyrronium is a new LAMA-LABA combination that is recently approved in a few countries around the world, including the USA. Herein, we discuss the efficacy and safety data behind this unique LABA-LAMA combination and its role in therapy of COPD. We will summarize the evidence behind the use of longacting bronchodilator therapy in COPD and will then focus on this particular combination in the treatment of COPD.

\section{Formoterol in COPD}

The treatment of symptomatic COPD patients historically involved short-acting bronchodilators, most commonly beta agonists. With the advent of salmeterol, and subsequently more than half-a-dozen LABA compounds, LABA has had a center stage in the treatment of COPD. A Cochrane database systematic review of 23 studies concluded in 2000 that LABA improves $\mathrm{FEV}_{1}$ and health-related quality-of-life while reducing the use of short-acting bronchodilators and the number of exacerbations. ${ }^{5}$

Formoterol was initially demonstrated to produce effective and sustained bronchodilation in COPD in open-label trials in the late 1980s. ${ }^{6}$ It was shown to have more sustained bronchodilation up to 12 hours compared to salbutamol ${ }^{7}$ and ipratropium. ${ }^{8}$ Subsequent double-blind randomized controlled trials have demonstrated its efficacy in the COPD population with improvements reported in $\mathrm{FEV}_{1}$ and exercise capacity. ${ }^{9-11}$

Formoterol has subsequently been used either alone as a Foradil Aerolizer ${ }^{\mathrm{TM}}$ or in combination with ICSs for the management of COPD. It was subsequently formulated in a proprietary porous lipid particle co-suspension metereddose inhaler (MDI) technology by Pearl Therapeutics (Morristown, NJ, USA; now a subsidiary of AstraZeneca) and has been shown to have comparable efficacy to formoterol delivered in an Aerolizer device. ${ }^{12}$

\section{Glycopyrronium in COPD}

Ipratropium bromide was the first short-acting antimuscarinic agent used in the management of COPD symptoms, based on a few small-scale studies in the last century. With the advent of long-acting form in tiotropium, LAMAs have been used extensively in the management of COPD, either as monotherapy in moderate COPD or as combination with
LABA-ICS in more advanced form of the disease. Several newer antimuscarininc agents have since been developed in the last decade, including aclidinium, umeclidinium, and glycopyrronium.

Interest in glycopyrrolate (glycopyrronium bromide) as a useful drug for relieving bronchospasm dates back to the 1980s, with case reports of its efficacy with intravenous use in the literature. ${ }^{13}$ The first randomized controlled trial demonstrating the efficacy of inhaled glycopyrrolate nebulization in addition to albuterol was performed in the 1990s. ${ }^{14}$ Subsequent studies of inhaled glycopyrronium demonstrated effective bronchodilation with early onset of action and sustained effect for 24 hours after use in patients with COPD at a dose of $50 \mu \mathrm{g}$ daily in a dry powder Breezhaler ${ }^{\mathrm{TM}}$ device (non-US version of Neohaler ${ }^{\mathrm{TM}}$ device). ${ }^{15}$ Several randomized controlled trials have since been conducted demonstrating efficacy of the compound in COPD patients.

GEM1 study was a 12-week randomized, double-blind, placebo-controlled study that randomized 441 patients with moderate-to-severe obstruction to glycopyrronium $15.6 \mu \mathrm{g}$ or placebo via Neohaler device; it demonstrated clinically significant improvement in lung function, dyspnea score, St George's Respiratory Questionnaire (SGRQ) score, COPD Assessment Test score, and rescue medication use with comparable side effects. The median time of onset of action of the medication was 18.8 min (for a change in $\mathrm{FEV}_{1}$ of at least $100 \mathrm{~mL}$ ), which might be beneficial for rapid symptom relief. A twice daily dosing was chosen in this study due to dose-ranging study showing increased efficacy in comparison to once daily dosing. ${ }^{16}$

GLOW1 and 2 randomized 1888 patients to glycopyrronium $50 \mu \mathrm{g}$ once daily in a dry powder inhaler via a Breezhaler device (NVA237), tiotropium $18 \mu \mathrm{g}$ once daily, or placebo for 26-52 weeks and demonstrated equivalent efficacy of glycopyrronium to tiotropium in terms of improvement in $\mathrm{FEV}_{1}$ and reduction in the rate of moderate-to-severe exacerbation. The effects were sustained through weeks 26 and 52 . The onset of action was more rapid compared to tiotropium. Common side effects included dry mouth, nasopharyngitis, cough, bacterial URTI, and headache. Major cardiovascular side effects were similar to placebo and tiotropium. ${ }^{17,18}$ This efficacy was redemonstrated in a predominantly Chinese population in the GLOW7 study that randomized patients to glycopyrronium or placebo. ${ }^{19}$

Since one of the major limiting factors in a patient with COPD is dyspnea and reduced exercise capacity, GLOW3 study was conducted to demonstrate the efficacy of glycopyrronium in improving exercise capacity. It demonstrated 
statistically significant improvement in ergometer exercise time after 21 days of the use of glycopyrronium $50 \mu \mathrm{g}$ once daily, as well as improvement in inspiratory capacity, thereby denoting decrease in air trapping. ${ }^{20}$ GLOW5 was a 12 -week randomized controlled trial comparing efficacy of glycopyrronium $50 \mu \mathrm{g}$ daily to tiotropium $18 \mu \mathrm{g}$ daily. It demonstrated that glycopyrronium was not only as effective as tiotropium in improving $\mathrm{FEV}_{1}$ and symptom scores at 12 weeks but also provided superior bronchodilation and improvement in $\mathrm{FEV}_{1}$ compared to tiotropium on day 1, demonstrating its rapid onset of action. ${ }^{21}$ GLISTEN study demonstrated the efficacy of glycopyrronium when added to salmeterol/ fluticasone combination. ${ }^{22}$ Finally, results are awaited from two studies (GOLDEN-3 and 4) evaluating the efficacy of nebulized glycopyrrolate (developed by Sunovion Pharmaceuticals Inc $^{\circledR}$, Marlborough, MA, USA).

Glycopyrronium bromide (glycopyrrolate) was subsequently developed in an inhaled MDI form by Pearl Therapeutics (subsidiary of AstraZeneca), which is referred to by its active ingredient glycopyrronium. It is formulated in a special porous particle comprising phosphatidylinositolcholine and calcium chloride, on which the active medication is adsorbed. This fine-particle formulation allows stability of the MDI formulation of the drug and homogenous delivery of the active medication into the distal airway. In the dosefinding pharmacokinetic study done on the MDI formulation of the drug, BID dosing was found to be most appropriate for sustained improvement in both the 1-12 hours FEV 1 and 12-24 hours $\mathrm{FEV}_{1}$, with total recommended daily dose of 57.6 and $115.2 \mu \mathrm{g} .{ }^{23}$

\section{Formoterol-glycopyrronium combination in COPD}

The mainstay of COPD management for the last one and a half decade has been the use of inhaled LAMA, with addition of the combination of ICS-LABA for more severe COPD or those with frequent exacerbations. Support for this approach comes from multiple trials and meta-analyses. However, we are now beginning to realize that not all patients with COPD need ICSs. The WISDOM study demonstrated this by withdrawing inhaled steroids from the regimen of stable patients with COPD and showed that there was no worsening of symptoms, exacerbation rate, or quality of life. ${ }^{4}$ However, ICSs come with their own risk. Multiple studies including a Cochrane database review have shown an increased risk of pneumonia with commonly used inhaled steroids. ${ }^{24}$ It hence seems logical that if the patients could be managed without inhaled steroids, while at the same time providing maximal bronchodilation and improved quality of life, then this should be the best course of action. This is true for patients who have severe activity limitation but are not frequent exacerbators. However, caution should be exercised when withdrawing steroids in patients who have been stable on LABA-ICS combination because a statistically significant decline in $\mathrm{FEV}_{1}$ was demonstrated after withdrawal of inhaled steroid in both the WISDOM study ${ }^{4}$ and the GLUCOLD study from the Netherlands. ${ }^{25}$

The efficacy of LAMA-LABA fixed-dose combination (FDC) was first studied with umeclidinium-vilanterol, which not only showed non-inferiority in control of symptoms but also showed superiority in at least one study. ${ }^{26}$ A Cochrane database review from 2015 concluded that there was a small increase in mean $\mathrm{FEV}_{1}$ and in health-related qualityof-life with addition of LABA to LAMA therapy. ${ }^{27}$ Several LAMA-LABA FDCs have since been developed, including glycopyrrolate/indacaterol, tiotropium/olodaterol, and aclidinium/formoterol. All of these FDCs were formulated either as dry-powder inhalers (DPIs) or as soft mist inhaler. Since MDIs remain a popular and widely familiar device for drug delivery, a novel MDI formulation of formoterol fumarate $(9.6 \mu \mathrm{g})$ and glycopyrronium $(18 \mu \mathrm{g})$ was developed utilizing the proprietary co-suspension technology. Drug particles were suspended in the hydroxyfluoralkalane (HFA) propellant using distearoyl-phosphatidylcholine particles. This formulation was developed to provide a homogenous distribution of the drug in an HFA medium without deposition of drug crystals. The combination has subsequently received approval in several countries including the USA, where it is currently marketed as the Bevespi Aerosphere ${ }^{\mathrm{TM}}$ by AstraZeneca.

PINNACLE 1 and 2 were both 24-week double-blind, placebo-controlled Phase III trials that compared the safety and side effects of the combination glycopyrronium/formoterol fumarate (GFF) MDI, used two puffs twice daily, to their individual monocomponents (GP MDI, glycopyrrolate $18 \mu \mathrm{g}$ and FF MDI, formoterol fumarate $9.6 \mu \mathrm{g}$ ), open-label tiotropium DPI (only in PINNACLE-1), and placebo. ${ }^{28}$ The combined sample size was 3,710 patients; $53 \%$ of whom had moderate obstruction (GOLD 2), 41\% had severe obstruction (GOLD 3), and 5\% had very severe obstruction (GOLD 4). The analysis involved 3,699 patients, of whom 3,001 (81\%) completed 24 weeks of treatment. GFF combination demonstrated improvement versus placebo and monocomponents in morning pre-dose trough FEV at 24 weeks $(P<0.0001)$ as well as in 2-hour post-dose $\mathrm{FEV}_{1}(P<0.0001)$ (Figure 1). Pooled SGRQ data demonstrated a reduction in total score 
A

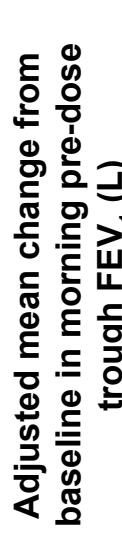

PINNACLE-1

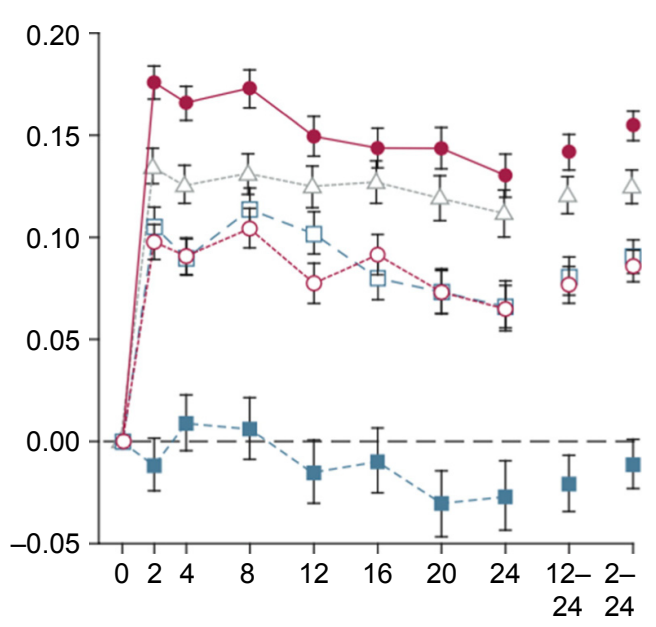

Number of weeks post-dose
B

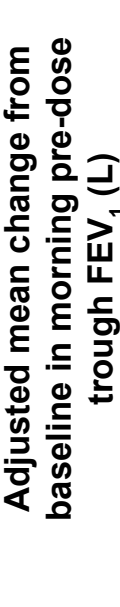

PINNACLE-2

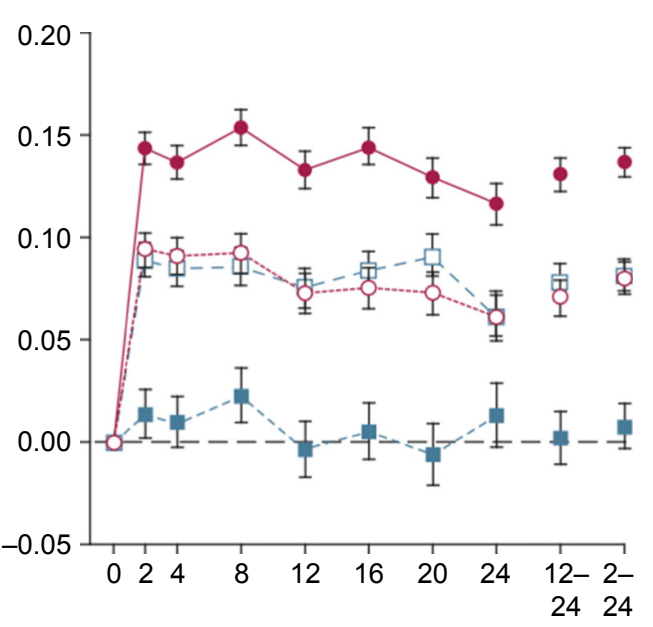

Number of weeks post-dose

$\bullet-$ GFF MDI --O-FF MDI - $\square-$ GP MDI - - - Placebo MDI $-\triangle-$ Open-label tiotropium

Figure I Mean change from baseline in morning pre-dose trough FEV in different treatment groups.

Note: Reprinted from Chest 2016;15I(2017), Martinez FJ, Rabe KF, Ferguson GT, et al, Efficacy and safety of glycopyrrolate/formoterol MDI formulated using Co-Suspension ${ }^{\mathrm{TM}}$ Delivery Technology in patients with COPD. Copyright (2016) The Authors, with permission from Elsevier. ${ }^{28}$

Abbreviations: FF, formoterol fumarate; GFF, glycopyrronium/formoterol fumarate; GP, glycopyrronium; MDI, metered-dose inhaler.

with GFF at week 24 versus placebo $(P=0.0051)$ and GP $(P<0.0094)$. Hazard ratio (HR) of time to first exacerbation was lower with GFF compared to placebo (HR 0.736, $P<0.002$ ) and glycopyrronium (HR 0.781, $P<0.002$ ), but not formoterol. See Table 1 for a summary of primary and secondary end points in both studies. Patients also needed less rescue inhaler medication use compared to placebo $(P<0.0001)$ or GP $(P<0.0001)$. Treatment emergent adverse effects were similar across all the active-treatment groups.
Those that were reported at a rate higher than the placebo were cough, sinusitis, COPD, back pain, and bronchitis. Adverse effect leading to discontinuation was highest in the placebo group. Cardiovascular side effects were low and comparable in all groups at $0.4 \%-0.7 \%$. All cause deaths were also comparable in all groups.

PINNACLE 3 was the extension of the previous two studies where 893 patients who completed the original studies continued the same treatment, including monocomponents

Table I Summary of primary and secondary end points and safety outcomes from the PINNACLE-I and PINNACLE-2 study

\begin{tabular}{|c|c|c|c|c|c|c|c|c|c|}
\hline \multirow[t]{2}{*}{ Efficacy parameters } & \multicolumn{5}{|c|}{ PINNACLE-I } & \multicolumn{4}{|c|}{ PINNACLE-2 } \\
\hline & GFF & GP & $\mathbf{F F}$ & Placebo & TIO & GFF & GP & $\mathbf{F F}$ & Placebo \\
\hline Change in trough $\mathrm{FEV}$, at week $24, \mathrm{~mL}$ & 126 & 66 & 62 & -24 & 105 & 116 & 63 & 61 & 13 \\
\hline $\begin{array}{l}\text { Change in } 2 \text { hours post-dose } F E V_{\text {, at }} \\
\text { week } 24, \mathrm{~mL}\end{array}$ & 356 & 223 & 263 & 65 & 259 & 350 & 223 & 268 & 83 \\
\hline Change in SGRQ at week 24 & -3.3 & -1.0 & -2.7 & -0.8 & -2.6 & -3.0 & -2.3 & -2.2 & -1.2 \\
\hline $\begin{array}{l}\text { Proportion of patients obtain MCID } \\
\text { in SGRQ at week } 24, \%\end{array}$ & 37.1 & 29.8 & 34.7 & 28.5 & 38.5 & 39.4 & 34.7 & 33.5 & 33.1 \\
\hline Change in daily albuterol use, puffs/day & -0.8 & -0.5 & -0.8 & 0.3 & -0.4 & -1.0 & -0.4 & -0.7 & 0.0 \\
\hline $\begin{array}{l}\text { Change in mean daily total symptom } \\
\text { score over } 24 \text { weeks }\end{array}$ & -0.8 & -0.1 & -0.5 & I & -0.5 & -1.0 & -0.4 & -0.6 & 0.4 \\
\hline Patients with adverse events, $\%$ & 62.9 & 58.8 & 59.5 & 62.7 & 62.7 & 56.1 & 53.5 & 54.1 & 52.5 \\
\hline Patients with serious adverse events, $\%$ & 12.4 & 12.4 & 13.1 & 14.1 & 10.2 & 10.2 & 9.8 & 8.9 & 6.7 \\
\hline $\begin{array}{l}\text { Patients with AE needing } \\
\text { discontinuation, \% }\end{array}$ & 7.4 & 7.3 & 4.9 & 6.4 & 4.9 & 4.9 & 4.8 & 5.7 & 8.5 \\
\hline
\end{tabular}

Note: Adapted from Chest 2016;15I(2017), Martinez FJ, Rabe KF, Ferguson GT, et al, Efficacy and safety of glycopyrrolate/formoterol MDI formulated using Co-Suspension TM Delivery Technology in patients with COPD. Copyright 2016 with permission from Elsevier. ${ }^{28}$

Abbreviations: AE, adverse event; FF, formoterol fumarate; GFF, glycopyrronium/formoterol fumarate; GP, glycopyrronium; MCID, minimal clinically important difference; TIO, open-label tiotropium; SGRQ, St George's Respiratory Questionnaire. 
and open-label tiotropium for another 52 weeks. There were no unexpected safety findings. Overall incidence of adverse events was similar across all groups $(60 \%-69 \%)$, with the most commonly reported events being nasopharyngitis $(6.8 \%)$, cough $(4.3 \%)$, and upper respiratory tract infection $(3.8 \%)$. GFF demonstrated significant improvement in trough and 2-hour post-dose peak $\mathrm{FEV}_{1}$ versus FF (65 and $88 \mathrm{~mL}$, respectively), GP (57 and $129 \mathrm{~mL}$, respectively), and tiotropium (25 and $93 \mathrm{~mL}$, respectively). GFF also demonstrated significant improvement versus GP $(P<0.001)$ and open-label tiotropium $(P=0.002)$ for average daily use of rescue medication. ${ }^{29}$

\section{Safety}

Long-acting bronchodilators have been found to be relatively safe in COPD patients in multiple other studies. In a large study of 1,429 patients treated with LABA arformoterol (Brovana nebulizer; Sunovion Pharmaceuticals; Marlborough, MA, USA) and salmeterol (Serevent inhalation aerosol, GlaxoSmithKline, Research Triangle Park, NC, USA) who underwent Holter monitoring, atrial tachycardia was found to be relatively common at baseline, but there was only marginal increase in atrial tachycardia with the use of beta agonists, and no increased risk of more serious arrhythmias including ventricular tachycardia. ${ }^{30}$ A randomized placebo-controlled trial was done to assess cardiac safety in COPD patients given formoterol $12 \mu \mathrm{g}$ twice daily showed very low evidence of ventricular arrhythmia in both groups, with no significant difference between the active and placebo groups. ${ }^{31}$ Inhaled tiotropium was demonstrated to be safe in multiple studies including the large-scale TIOSPIR trial. ${ }^{32}$ Similarly, the cardiac safety of glycopyrronium has been demonstrated in multiple randomized controlled trials, with no increase in cardiac side effects over placebo. ${ }^{33,34}$ The PINNACLE studies demonstrated acceptable safety profile of the GFF combination compared to its monocomponents as detailed above and as detailed in Table 1.

\section{Conclusions}

In conclusion, the formoterol-glycopyrronium combination MDI appears to be a safe and effective treatment option for moderate-to-severe COPD in terms of symptoms reduction, improvement of quality-of-life, and decreasing the frequency of exacerbations. The newly developed proprietary porous particle technology allows the drug to be formulated in an MDI form, which is a widely familiar device to the COPD patients. This new drug formulation in a familiar delivery system should be a good alternative to maximize bronchodilation in patients with COPD.

\section{Acknowledgments}

Dr Criner reports grants from Boehringer-Ingelheim, Novartis, Astra Zeneca, Respironics, MedImmune, Actelion, Forest, Pearl, Ikaria, Aeris, PneumRx, and Pulmonx and consultation fees from Amirall, Boehringer-Ingelheim, and Holaira. Dr Dhungana reports grants from Oncocyte.

\section{Disclosure}

The authors report no conflicts of interest in this work.

\section{References}

1. WHO. Projections of mortality and causes of death, 2015 and 2030. WHO. 2014. Available from: http://www.who.int/healthinfo/global_ burden_disease/projections/en; accessed April 17, 2017.

2. Mathers CD, Loncar D. Projections of global mortality and burden of disease from 2002 to 2030. PLoS Med. 2015;3(11):e442.

3. Global Initiative for Obstructive Lung Disease. Global strategy for the diagnosis, management and prevention of chronic obstructive pulmonary disease. GOLD. 2017. Available from: http://www. goldcopd.org. 2017. Accessed April 17, 2017.

4. Magnussen H, Disse B, Rodriguez-Roisin R, et al. Withdrawal of inhaled glucocorticoids and exacerbations of COPD. $N$ Engl J Med. 2014;371(14):1285-1294.

5. Appleton S, Poole P, Smith BJ, et al. Long-acting beta2-agonists for poorly reversible chronic obstructive pulmonary disease. Cochrane Database of Systematic Reviews. 2006;(3):CD001104.

6. Schultze-Werninghaus G. Multicenter 1-year trial on formoterol, a new long-acting $\beta 2$-agonist, in chronic obstructive airway disease. Lung. 1990;168(1):83-89.

7. Maesen FP, Smeets JJ, Gubbelmans HLL, Zweers PG. Bronchodilator effect of inhaled formoterol versus salbutamol over 12 hours. Chest. 1990;97(3):590-594.

8. Dahl R, Greefhorst LA, Nowak D, et al. Inhaled formoterol dry powder versus ipratropium bromide in chronic obstructive pulmonary disease. Am J Respir Crit Care Med. 2001;164(5):778-784.

9. Fuso L, Incalzi RA, Basso S, et al. Effects of formoterol inhaled dry powder on exercise performance in chronic obstructive pulmonary disease: a single-center, randomized, double-blind, placebo-controlled, crossover study. Curr Ther Res Clin Exp. 2003;64(5):317-326.

10. Aalbers R, Ayres J, Backer V, et al. Formoterol in patients with chronic obstructive pulmonary disease: a randomized, controlled, 3-month trial Eur Respir J. 2002;19(5):936-943.

11. Campbell M, Eliraz A, Johansson G, et al. Formoterol for maintenance and as-needed treatment of chronic obstructive pulmonary disease. Respir Med. 2005;99(12):1511-1520.

12. Quinn D, Seale JP, Reisner C, et al. A randomized study of formoterol fumarate in a porous particle metered-dose inhaler in patients with moderate-to-severe COPD. Respir Med. 2014;108(9):1327-1335.

13. Slovis CM, Daniels GM, Wharton DR. Intravenous use of glycopyrrolate in acute respiratory distress due to bronchospastic pulmonary disease. Ann Emerg Med. 1987;16(8):898-900.

14. Cydulka RK, Emerman CL. Effects of combined treatment with glycopyrrolate and albuterol in acute exacerbation of chronic obstructive pulmonary disease. Ann Emerg Med. 1995;25(4):470-473. Available from: http://ovidsp.ovid.com/ovidweb.cgi?T=JS\&PAGE=reference\& $\mathrm{D}=\mathrm{cctr} \& N E W S=\mathrm{N} \& A N=\mathrm{CN}-00112786$. Accessed April 17, 2017.

15. Fogarty C, Hattersley H, Di L, Drollmann A. Bronchodilatory effects of NVA237, a once daily long-acting muscarinic antagonist, in COPD patients. Respir Med. 2011;105(3):337-342.

16. LaForce C, Feldman G, Spangenthal S, et al. Efficacy and safety of twice-daily glycopyrrolate in patients with stable, symptomatic COPD with moderate-to-severe airflow limitation: the GEMI study. Int J COPD. 2016;11(1):1233-1243. 
17. D'Urzo A, Ferguson GT, van Noord JA, et al. Efficacy and safety of once-daily NVA237 in patients with moderate-to-severe COPD: the GLOW1 trial. Respir Res. 2011;12(1):156.

18. Kerwin E, Hébert J, Gallagher N, et al. Efficacy and safety of NVA237 versus placebo and tiotropium in patients with COPD: the GLOW2 study. Eur Respir J. 2012;40(5):1106-1114.

19. Wang C, Sun T, Huang Y, et al. Effcacy and safety of once-daily glycopyrronium in predominantly Chinese patients with moderateto-severe chronic obstructive pulmonary disease: the GLOW7 study. Int J COPD. 2015;10:57-68.

20. Beeh KM, Singh D, Di Scala L, Drollmann A. Once-daily NVA237 improves exercise tolerance from the first dose in patients with COPD: the GLOW3 trial. Int J COPD. 2012;7:503-513.

21. Chapman KR, Beeh K, Beier J, et al. A blinded evaluation of the efficacy and safety of glycopyrronium, a once-daily long-acting muscarinic antagonist, versus tiotropium, in patients with COPD: the GLOW5 study. BMC Pulm Med. 2014;14(1):1-11.

22. Frith PA, Thompson PJ, Ratnavadivel R, et al. Glycopyrronium oncedaily significantly improves lung function and health status when combined with salmeterol/fluticasone in patients with COPD: the GLISTEN study, a randomised controlled trial. Thorax. 2015;70(6):519-527.

23. Rennard S, Fogarty C, Reisner C, et al. Randomized study of the safety, pharmacokinetics, and bronchodilatory efficacy of a proprietary glycopyrronium metered-dose inhaler in study patients with chronic obstructive pulmonary disease. BMC Pulm Med. 2014;14(1):118.

24. Kew KM, Seniukovich A. Inhaled steroids and risk of pneumonia for chronic obstructive pulmonary disease. Cochrane Database Syst Rev. 2014;10(3):CD010115.

25. Kunz LIZ, Postma DS, Klooster K, et al. Relapse in FEV Decline After Steroid Withdrawal in COPD. Chest. 2015;148(2):389-396.

26. Singh D, Worsley S, Zhu C, Hardaker L, Church A. Umeclidinium/ vilanterol versus fluticasone propionate/salmeterol in COPD: a randomised trial. BMC Pulm Med. 2015;15:91.
27. Farne HA, Cates CJ. Long-acting beta 2-agonist in addition to tiotropium versus either tiotropium or long-acting beta 2-agonist alone for chronic obstructive pulmonary disease. Cochrane Database Syst Rev. 2015; 10(10):CD008989.

28. Martinez FJ, Rabe KF, Ferguson GT, et al. Efficacy and safety of glycopyrrolate/formoterol MDI formulated using Co-Suspension ${ }^{\mathrm{TM}}$ Delivery Technology in patients with COPD. Chest. 2016;151(2017): 340-357.

29. Hanania NA, Tashkin DP, Kerwin E, et al. Safety and efficacy of a novel LAMA/LABA co-suspension technology Glycopyrrolate/ Formoterol fixed-dose combination delivered by MDI: results of a oneyear extension study in patients with COPD (PINNACLE-3). In: D36. COPD: LABA, LAMA, ICS, and combinations. American Thoracic Society International Conference Abstracts. American Thoracic Society; 2016:A6791-A6791.

30. Hanrahan JP, Grogan DR, Baumgartner RA, et al. Arrhythmias in patients with chronic obstructive pulmonary disease (COPD). Medicine (Baltimore). 2008;87(6):319-328.

31. Campbell SC, Criner GJ, Levine BE, et al. Cardiac safety of formoterol 12 microg twice daily in patients with chronic obstructive pulmonary disease. Pulm Pharmacol Ther. 2007;20(5):571-579.

32. Wise RA, Anzueto A, Cotton D, et al. Tiotropium Respimat inhaler and the risk of death in COPD. $N$ Engl J Med. 2013;369(16): 1491-1501.

33. Van de Maele B, Fabbri LM, Martin C, Horton R, Dolker M, Overend T. Cardiovascular safety of QVA149, a combination of Indacaterol and NVA237, in COPD patients. COPD. 2010;7(6):418-427.

34. Vogelmeier C, Verkindre C, Cheung D, et al. Safety and tolerability of NVA237, a once-daily long-acting muscarinic antagonist, in COPD patients. Pulm Pharmacol Ther. 2010;23(5):438-444.
International Journal of COPD

\section{Publish your work in this journal}

The International Journal of COPD is an international, peer-reviewed journal of therapeutics and pharmacology focusing on concise rapid reporting of clinical studies and reviews in COPD. Special focus is given to the pathophysiological processes underlying the disease, intervention programs, patient focused education, and self management protocols.

\section{Dovepress}

This journal is indexed on PubMed Central, MedLine and CAS. The manuscript management system is completely online and includes a very quick and fair peer-review system, which is all easy to use. Visit http://www.dovepress.com/testimonials.php to read real quotes from published authors. 